\title{
Sox2: a possible driver of the basal-like phenotype in sporadic breast cancer
}

\author{
Socorro M Rodriguez-Pinilla ${ }^{1,2}$, David Sarrioº ${ }^{1}$ Gema Moreno-Bueno ${ }^{1}$, \\ Yolanda Rodriguez-Gil ${ }^{3}$, Miguel A Martinez ${ }^{3}$, Lucia Hernandez ${ }^{3}$, David Hardisson ${ }^{4}$, \\ Jorge S Reis-Filho ${ }^{2}$ and Jose Palacios ${ }^{1}$
}

\begin{abstract}
${ }^{1}$ Laboratory of Breast and Gynaecological Cancer, Molecular Pathology Programme, Centro Nacional de Investigaciones Oncológicas (CNIO), Madrid, Spain; ${ }^{2}$ The Breakthrough Breast Cancer Research Centre, Institute of Cancer Research, London, UK; ${ }^{3}$ Pathology Department, Hospital Universitario 12 de octubre, Madrid, Spain and ${ }^{4}$ Pathology Department, Hospital Universitario La Paz, Madrid, Spain
\end{abstract}

\begin{abstract}
Tumours arising in BRCA1 mutation carriers and sporadic basal-like breast carcinomas have similar phenotypic, immunohistochemical and clinical characteristics. SOX2 is an embryonic transcription factor located at chromosome 3q, a region frequently gained in sporadic basal-like and BRCA1 germline mutated tumours. The aim of the study was to establish whether sox2 expression was related to basal-like sporadic breast tumours. Two hundred and twenty-six sporadic node-negative invasive breast carcinomas were immunohistochemically analysed for oestrogen receptor (ER), progesterone receptor (PR), CK5/6, EGFR, vimentin, HER2, ki67, p53 and sox2 using tissue microarrays. Tumours were considered to have basal-like phenotype if they were ER/HER2-negative and CK5/6 and/or EGFR-positive. Thirty cases of this series (13.7\%) displayed a basal-like phenotype. Sox2 expression was observed in $\mathbf{1 6 . 7 \%}$ of cases and was significantly more frequently expressed in basal-like breast carcinomas $(43.3 \%$ in basal-like, $10.6 \%$ in luminal and $13.3 \%$ in HER2 + tumours, $P<0.001)$. Moreover, Sox 2 showed a statistically significant inverse association with ER and PR $(P=0.001$ and 0.017 , respectively) and direct association with CK5/6, EGFR and vimentin $(P=0.022,0.005$ and $<0.001$, respectively). Sox2 is preferentially expressed in tumours with basal-like phenotype and may play a role in defining their less differentiated/'stem cell' phenotypic characteristics.
\end{abstract}

Modern Pathology (2007) 20, 474-481. doi:10.1038/modpathol.3800760; published online 2 March 2007

Keywords: SOX2; basal-like phenotype; node-negative breast carcinomas; immunohistochemistry; tissue microarray

Breast cancer is a heterogeneous disease encompassing a wide variety of pathological entities and a range of clinical behaviour. ${ }^{1}$ Recent cDNA microarray studies have demonstrated that breast cancers can be classified according to their gene expression profiles into four main groups: basal-like, luminal (A and B), HER2 + and normal breast-like carcinomas. ${ }^{1}$ Importantly, these groups have been shown to be of prognostic and predictive significance. Basal-like breast carcinomas are of high grade, lack

Correspondence: Dr SM Rodríguez-Pinilla, MD, Laboratory of Breast and Gynaecological Cancer, Molecular Pathology Programme, Centro Nacional de Investigaciones Oncológicas (CNIO), Melchor Fernández Almagro, 28029 Madrid, Spain.

E-mail: smrodriguez@yahoo.es or

Current address: Dr J Palacios, Servicio de Anatomía Patológica, HHUU Virgen del Rocío, Manuel Siurot S/N, 41013 Sevilla, Spain.

E-mail: jose.palacios.sspa@juntadeandalucia.es

Received 13 November 2006; revised 16 January 2007; accepted 18 January 2007; published online 2 March 2007 oestrogen receptor (ER) and HER2 expression, and are consistently positive for basal keratins and/or other markers normally expressed by basal/myoepithelial cells. ${ }^{1-9}$ Moreover, they characteristically overexpress cyclin E and show p53 immunoexpression. Historically, this phenotype was associated to breast carcinomas with a characteristic pattern of growth (consisting of a central area of necrosis and/ or fibroelastosis surrounded by a ribbon of neoplastic growing at the periphery), and showing a poor prognosis and a peculiar proclivity for visceral metastasis, mainly to the lung and brain.,.$^{2,40-14}$ Recently, several studies ${ }^{9,15-20}$ have demonstrated that basal-like carcinomas are characterised at the histological level by the presence of central scar, tumour necrosis, high proliferation rates, metaplastic elements (ie, spindle and squamous cells) and atypical medullary features. Therefore, it is not surprising that both metaplastic and typical/atypical medullary carcinomas have also been shown to belong to this subgroup of tumours..$^{19,20}$ 
The similarities between basal-like breast carcinomas and tumours arising in BRCA1 germline mutation carriers are overwhelming. ${ }^{21-24}$ BRCA1 tumours clustered together with sporadic basal-like tumours in cDNA microarrays studies. ${ }^{3}$ Moreover, these tumours also share immunohistochemical, morphological and biological characteristics, including the predisposition to visceral metastasis and better response to chemotherapy than other subgroup of tumours. ${ }^{25,26}$ On the basis of these lines of evidence, many authors have suggested that BRCA1 gene and/or BRCA1 pathway ${ }^{27}$ are inactivated in basal-like sporadic tumours, which has been confirmed recently. ${ }^{28}$

SOX2 gene, located in chromosome 3q26.33, encodes for a member of the HMG-domain DNAbinding protein family. It has been demonstrated recently that sox2 may control the expression of several genes that play pivotal roles in embryonic development, including nanog homeobox, nestin, $\delta$-crystalline, fibroblast growth factor 4 , undifferentiated embryonal cell transcription factor 1 and F-box containing protein 15. Moreover, its function is highly related to the expression of the $P O U$ domain class 5 transcription factor 1 (aka, OCT-4), another gene implicated in maintaining stem cell properties. SOX2 downregulation correlates with loss of pluripotency and self-renewal, and the activation of subsequent differentiation steps. ${ }^{29-36}$ Furthermore, SOX2 has been implicated as a target of WNT, TGFB, FGF, BMP and NODAL signalling pathways during embryogenesis. ${ }^{37-41}$ SOX2 gene expression has not been studied in breast cancer; however, gains of genomic material on the long arm of chromosome 3 (3q) are frequently found in tumours arising in BRCA1 germ-line mutation carriers $^{42,43}$ and in sporadic basal-like breast cancer. ${ }^{44}$

Although there is no internationally agreement about the immunohistochemical definition of sporadic basal-like breast carcinomas, Nielsen et al ${ }^{6}$ have demonstrated that a panel of four antibodies (ER, HER2, CK5/6 and EGFR) identifies these tumours with high specificity. Given the role played by sox2 in the maintenance of stem cells and the fact that basal-like cancers express multiple lineage markers (ie, luminal and basal keratins, vimentin, myoid markers) and frequently display metaplastic elements, we hypothesised that sox2 would be preferentially expressed in this subgroup of breast carcinomas. The aim of this study was to determine whether sox2 protein expression correlates with basal-like phenotype, according to Nielsen et al. criteria, ${ }^{6}$ in a cohort of 226 node-negative invasive breast carcinomas.

\section{Materials and methods}

\section{Tumour Samples}

We analysed a group of 226 node-negative sporadic breast carcinomas diagnosed in Hospital Universi- tario La Paz, Madrid between 1988 and 2002. None of the patients had family history suggestive of familial/hereditary cancer. ${ }^{45}$ Some of the clinicopathological characteristics of this series, including age, treatment, survival of the patients, as well as size, grade, histological subtype and some immunohistochemical characteristics of the tumours (oestrogen (ER) and progesterone receptors (PR), ki67, p53, HER2, CK5/6, EGFR and vimentin) have been reported previously. ${ }^{14,46}$ The study was carried out with the approval of the 'Hospital La Paz' ethical committee.

\section{Tissue Microarray Construction}

Representative areas from formalin-fixed, paraffinembedded infiltrating carcinomas and 30 samples from non-neoplastic breast tissue were carefully selected on H\&E-stained sections and two 1-mmdiameter tissue cores were obtained from each specimen. The tissue cores were precisely arrayed into a new paraffin block using a tissue microarray workstation (Beecher Instruments, Silver Spring, MD).

\section{Immunohistochemistry}

Immunohistochemical staining on tissue microarray (TMAs) sections was performed using the EnVision method as described previously. Antibodies, clones, dilutions, antigen-retrieval methods and scoring systems for ER, PR, HER2, CK5/6, EGFR, vimentin, ki67 and p53 are described elsewhere. ${ }^{14,46}$ Rabbit anti-sox2 polyclonal antibody was applied at dilution of 1:100 (sox2, Stem-cell Technologies). After a preheating step for antigen retrieval, TMA sections were immersed in boiling $10 \mathrm{mmol} / \mathrm{l}$ sodium citrate at $\mathrm{pH} 6.5$ for $2 \mathrm{~min}$ in a pressure cooker. Cases were considered positive for sox 2 when any unequivocal neoplastic cell displayed definite nuclear staining. Normal breast control cores on the TMA were used as internal controls. Positive (ie, normal breast tissue) and negative controls (ie, omission of the primary antibody and/or IgG-matched serum) were included in each slide run.

Tumours were subdivided according to the Nielsen et al classification as: basal-like (ER and HER2negative and CK5/6 and/or EGFR-positive), luminal (ER-positive and HER2-negative) and HER2-positive subgroups. ${ }^{6}$

\section{Statistical Analysis}

To test associations between categorical variables we used the $\chi^{2}$ or Fisher's exact test. Values of $P<0.05$ were considered significant. All tests were two-tailed and $95 \%$ confidence intervals were adopted. These analyses were carried out using the SPSS 12.0 for Windows statistical program (SPSS Inc., Chicago, IL). 


\section{Results}

The correlations between sox 2 expression, clinicopathological features and immunohistochemical markers studied in this series are summarised in Table 1.

Using the criteria proposed by Nielsen et al, ${ }^{6} 30$ cases $(13.7 \%), 17(7.8 \%)$ and $156(71.2 \%)$ were classified as basal-like, HER2 and luminal cancers, respectively. Sixteen cases $(7.3 \%)$ did not fulfil any of the above criteria and were excluded from the analysis. Sox2 nuclear expression was found in 33/198 (16.7\%) node-negative breast carcinomas. Basal-like breast carcinomas showed a statistically significant higher prevalence of sox2 expression when compared to that seen in the other groups (Table 1, Figure 1): 13/30 basal-like breast carcinomas $(43.3 \%)$ displayed sox2 immunoreactivity, whereas sox2 expression was seen in only $13.3 \%$ (2/15) of HER2 tumours and in $10.6 \%(14 / 132)$ of luminal tumours cancers $(P<0.0001)$.

Sox2 expression was directly correlated with tumour size and expression of CK5/6, EGFR and vimentin, and inversely correlated with ER and PR expression.

Taken together, these findings demonstrate that sox2 is preferentially expressed in basal-like carcinomas. However, in a way akin to other proteins involved in the biology of basal-like carcinomas (eg, caveolin $1,{ }^{47} 14-3-3 \sigma^{48}$ ), sox2 expression is not restricted to basal-like cancers, given that up to $10 \%$ of ER-positive tumours and up to $13 \%$ of HER2 + showed positivity for sox2.

\section{Discussion}

It has been demonstrated that tumours arising in BRCA1 germline mutation carriers show significant histological, immunohistochemical expression profile and molecular genetic differences when compared to sporadic breast carcinomas. However, with the more comprehensive characterisation of basallike breast carcinomas, it has become clear that tumours arising in BRCA1 germline mutation carriers and sporadic basal-like breast carcinomas have genotypic and phenotypic traits that are remarkably similar. $^{2,3,7,8,10,11,14,16-20,22,23,27,28,49-58}$

Comparative genomic hybridisation (CGH) analysis has demonstrated that $3 q$ copy number gains were an independent predictor of poor prognosis in a cohort of 76 sporadic node-negative breast tumours $^{59}$ and that these gains are significantly more prevalent in tumours arising in BRCA1 mutation carriers. ${ }^{42,43}$ In addition, gains of the telomeric region of $3 \mathrm{q}$ are seen in approximately $20 \%$ of basal-like cancers and $10 \%$ of luminal tumours. ${ }^{44}$

Sox2, a transcription factor located on 3q26.3-q27, is one of the transcription factors expressed by stem cells. There is growing evidence to suggest that this gene is essential for the maintenance of stem cell proliferation and differentiation capabilities, and it is not expressed in mature differentiated cells. ${ }^{29-41,60}$ Its role in carcinogenesis is poorly understood, although deregulation of homeobox gene expression has been implicated in the determining phenotypic expression of gastric, ampullar and pancreatic neoplastic cells and in the biology of cancers arising in these anatomical sites. ${ }^{61-67}$ Furthermore, expression analysis studies have shown that SOX2 is one of the genes differentially expressed between embryonal carcinomas and seminomas. Previous studies $^{39}$ have suggested that neoplastic cells of seminomas have phenotypic characteristics similar to those of undifferentiated germ cells, whereas embryonal carcinoma cells resemble pluripotent embryonic stem cells, which have the ability to differentiate. $^{39}$ Moreover, SOX2 has been shown recently to be amplified in prostate cancers. ${ }^{68}$

In our series, sox2 nuclear expression was strongly associated with basal-like phenotype $(P<0.001)$. Bertucci et $a l^{69}$ have demonstrated a highly significant overrepresentation of genes located on 12p13 and 6p21.3 in basal-like tumours, including several genes related to stem cell biology, such as NANOG, GDF3, STELLA, DPPA3, CD9 and $E D R$ and OCT4/POU5F1, respectively. 12p13 cytogenetic band is reported to be a hots-pot region for structural chromosomal changes associated with germ cell tumours. ${ }^{39}$ Although previous chromosomal CGH studies did not reveal gains of genomic material on 12p13 and/or 6p21.3 as a frequent event in basal-like and BRCA1 tumours, ${ }^{55,70}$ more recent array CGH and fluorescent in situ hybridisation analysis have demonstrated that gains of genomic material on 6 p21 and amplification of 12 p13 are preferentially found in basal-like breast cancers. ${ }^{44,71}$ These discrepancies may be because of the low resolution of chromosomal CGH and to the different definitions for basal-like cancers employed in these studies. ${ }^{4455,70,71}$ Interestingly, some of stem cell-related genes mapping to $12 \mathrm{p} 13$, are reported to be upregulated by SOX2 gene expression and, on the other hand, sox2 is directly regulated by OCT $4,{ }^{31,33,35,36,40}$ which maps to $6 \mathrm{p} 21$. Taken together, these findings suggest that in both sporadic basal-like carcinomas and tumours arising in BRCA1 germline mutation carriers, sox2 expression may be either driven by SOX2 gene copy number gains or OCT4 gene-mediated SOX2 transcriptional activation. Therefore, it seems clear that further studies are required to clarify the mechanism of sox2 expression in basal-like breast cancers.

Sox2 expression in our series was strongly correlated to CK5/6, EGFR and vimentin immunoreactivity. Both CK5/6 and EGFR proteins have been reported to be expressed by both normal mammary myoepithelial and epithelial cells ${ }^{5,72,73}$ and, when included in a immunohistochemical panel together with ER and HER2, these proteins define with high specificity the basal-like phenotype in both sporadic and in tumour arising in BRCA1 germline mutation carriers. ${ }^{6,8,21,51-53}$ Vimentin is highly characteristic of 
Table 1 Correlations between sox2 expression and clinicopathological and immunohistochemical features in node-negative breast carcinomas

\begin{tabular}{|c|c|c|c|}
\hline & Sox2 negative $(\mathrm{n}=165)$ & Sox 2 positive $(\mathrm{n}=33)$ & $\mathrm{P}$ \\
\hline Menopausal status & 70/84 (83.3\%) & 14/84 (16.7\%) & \\
\hline Premenopausal & $88 / 106(83.0 \%)$ & $18 / 106(17.0 \%)$ & 1 \\
\hline Postmenopausal & & & \\
\hline \multicolumn{4}{|l|}{ Size } \\
\hline p T1 & 86/98 (87.8\%) & $12 / 98(12.2 \%)$ & \\
\hline $\mathrm{p}$ T2 & $49 / 67(73.1 \%)$ & $18 / 67(26.9 \%)$ & 0.023 \\
\hline \multicolumn{4}{|l|}{ Histological grade } \\
\hline Grade 1 & 43/45 (95.6\%) & $2 / 45(4.4 \%)$ & \\
\hline Grade 2 & $40 / 49(81.6 \%)$ & 9/49 (18.4\%) & \\
\hline Grade 3 & $65 / 81(80.2 \%)$ & $16 / 81(19.8 \%)$ & 0.059 \\
\hline \multicolumn{4}{|l|}{ Clinical phenotype $^{a}$} \\
\hline Basal-like & 17/30 (56.7\%) & 13/30 (43.3\%) & \\
\hline Luminal & 118/132 (89.4\%) & 14/132 (10.6\%) & \\
\hline HER2+ & $13 / 15(86.7 \%)$ & $2 / 15(13.3 \%)$ & $<0.001$ \\
\hline \multicolumn{4}{|l|}{ Oestrogen receptor } \\
\hline Negative & 41/59 (69.5\%) & 18/59 (30.5\%) & \\
\hline Positive & $123 / 138(89.1 \%)$ & 15/138 (10.9\%) & 0.001 \\
\hline \multicolumn{4}{|c|}{ Progesterone receptor } \\
\hline Negative & $52 / 70(74.3 \%)$ & 18/70 (25.7\%) & \\
\hline Positive & $111 / 126(88.1 \%)$ & $15 / 126(11.9 \%)$ & 0.017 \\
\hline \multicolumn{4}{|l|}{ HER2 } \\
\hline Negative & 151/182 (83.0\%) & $31 / 182(17.0 \%)$ & \\
\hline Positive & $14 / 16(87.5 \%)$ & $2 / 16(12.5 \%)$ & 0.1 \\
\hline \multicolumn{4}{|l|}{ p53 } \\
\hline Negative & 118/139 (84.6\%) & $21 / 139(15.1 \%)$ & \\
\hline Positive & $45 / 57(78.9 \%)$ & $12 / 57(21.1 \%)$ & 0.4 \\
\hline \multicolumn{4}{|l|}{ Ki67 } \\
\hline Negative & $132 / 156(84.6 \%)$ & $24 / 156(15.4 \%)$ & \\
\hline Positive & $33 / 42(78.6 \%)$ & $9 / 42(21.4 \%)$ & 0.356 \\
\hline \multicolumn{4}{|l|}{ EGFR } \\
\hline Negative & 149/173 (86.1\%) & 24/173 (13.9\%) & \\
\hline Positive & $11 / 19(57.9 \%)$ & $8 / 19(42.1 \%)$ & 0.005 \\
\hline \multicolumn{4}{|l|}{$C K 5 / 6$} \\
\hline Negative & 140/162 (86.4\%) & 22/162 (13.6\%) & \\
\hline Positive & $24 / 35(68.6 \%)$ & 11/35 (31.4\%) & 0.022 \\
\hline \multicolumn{4}{|l|}{ Vimentin } \\
\hline Negative & 132/148 (89.2\%) & 16/148 (10.8\%) & \\
\hline Positive & $32 / 49(65.3 \%)$ & $17 / 49$ (34.7\%) & $<0.001$ \\
\hline
\end{tabular}

CK5/6: cytokeratin 5/6; EGFR: epidermal growth factor receptor.

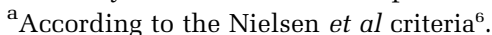

all immature primitive cells, and in normal breast its expression is restricted to mesenchymal and myoepithelial cells. ${ }^{72,73,74}$ Its expression in breast tumours has been also related to a basal-like phenotype in both sporadic and familial tumours. ${ }^{9,46,74,75}$ Several explanations have been put forward for the existence of breast cancers expressing both myoepithelial/mesenchymal and luminal markers: some have suggested that these lesions have a 'stem cell phenotype' and therefore would be able to be different towards different lineages, whereas others have speculated that this may reflect the ability of these cells to undergo epithelial-mesenchymal transition or to activate a basal/myoepithelial differentiation programme..$^{5,8,19,54,57,58,76}$

Given the previously reported functions of SOX2, our results suggest that sox 2 expression may play a role in conferring a less differentiated phenotype in these tumours or to activate the ability to differentiate in both luminal and basal/myoepithelial lineages.

In conclusion, our findings suggest that sox2 expression, a stem cell transcription factor, located in a frequently gained genomic region of $B R C A 1$ 

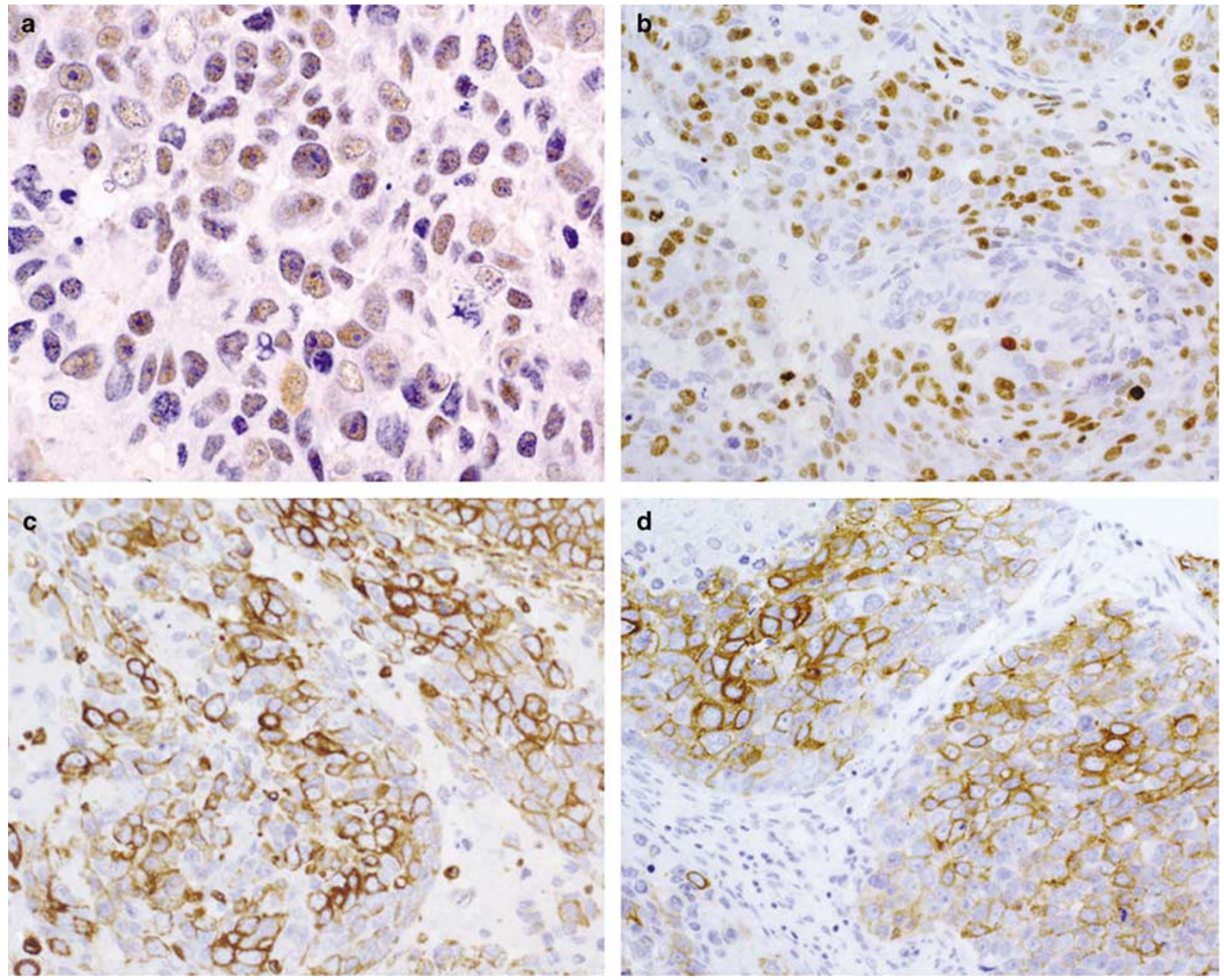

Figure 1 Expression of proteins studied by immunohistochemistry on tissue microarrays. Expression of sox2 (a), ki67 (b), vimentin (c) and CK5/6 (d), in one case of sporadic, lymph node negative, grade 3 invasive ductal carcinoma with basal-like phenotype. Original magnification: (a) $\times 400$; and (b-d) $\times 200$.

familial cancers and sporadic basal-like cancers, may play a role in the biology of basal-like breast carcinomas.

\section{Acknowledgements}

This study was supported by the Spanish Ministry of Education and Science (SAF2004-08258-C02-01) and the Instituto de Salud Carlos III (PI051890). Socorro María Rodríguez-Pinilla and David Sarrió are recipients of research grants from the Fondo de Investigación Sanitaria, Spain. Gema Moreno Bueno is a junior investigator of the Ramón y Cajal Programme (2004).

\section{References}

1 Perou CM, Sorlie T, Eisen MB, et al. Molecular portraits of human breast tumours. Nature 2000;406: 747-752.
2 Sorlie T, Perou CM, Tibshirani R, et al. Gene expression patterns of breast carcinomas distinguish tumor subclasses with clinical implications. Proc Natl Acad Sci USA 2001;98:10869-10874.

3 Sorlie T, Tibshirani R, Parker J, et al. Repeated observation of breast tumor subtypes in independent gene expression data sets. Proc Natl Acad Sci USA 2003;100:8418-8423.

4 Sotiriou C, Neo SY, McShane LM, et al. Breast cancer classification and prognosis based on gene expression profiles from a population-based study. Proc Natl Acad Sci USA 2003;100:10393-10398.

5 Gusterson BA, Ross DT, Heath VJ, et al. Basal cytokeratins and their relationship to the cellular origin and functional classification of breast cancer. Breast Cancer Res 2005;7:143-148.

6 Nielsen TO, Hsu FD, Jensen K, et al. Immunohistochemical and clinical characterisation of the basal-like subtype of invasive breast carcinoma. Clin Cancer Res 2004;10:5367-5374.

7 Abd El-Rehim DM, Ball G, Pinder SE, et al. Highthroughput protein expression analysis using tissue microarray technology of a large well-characterised series identifies biologically distinct classes of breast 
cancer confirming recent cDNA expression analyses. Int J Cancer 2005;116:340-350.

8 Abd El-Rehim DM, Pinder SE, Paish CE, et al. Expression of luminal and basal cytokeratins in human breast carcinoma. J Pathol 2004;203:661-671.

9 Livasy CA, Karaca G, Nanda R, et al. Phenotypic evaluation of the basal-like subtype of invasive breast carcinoma. Mod Pathol 2006;19:264-271.

10 van de Rijn M, Perou CM, Tibshirani R, et al. Expression of cytokeratins 17 and 5 identifies a group of breast carcinomas with poor clinical outcome. Am J Pathol 2002;161:1991-1996.

11 Banerjee S, Reis-Filho JS, Ashley S, et al. Basal-like breast carcinomas: clinical outcome and response to chemotherapy. J Clin Pathol 2006;59:729-735.

12 Gamallo C, Moreno-Bueno G, Sarrio D, et al. The prognostic significance of $\mathrm{P}$-cadherin in infiltrating ductal breast carcinoma. Mod Pathol 2001;14:650-654.

13 Rouzier R, Perou CM, Symmans WF, et al. Breast cancer molecular subtypes respond differently to preoperative chemotherapy. Clin Cancer Res 2005;11: 5678-5685

14 Rodriguez-Pinilla SM, Sarrio D, Honrado E, et al. Prognostic significance of basal-like phenotype and fascin expression in node-negative invasive breast carcinomas. Clin Cancer Res 2006;12:1533-1539.

15 Palacios J, Benito N, Pizarro A, et al. Anomalous expression of P-cadherin in breast carcinoma. Correlation with e-cadherin expression and pathological features. Am J Pathol 1995;146:605-612.

16 Rakha EA, Putti TC, Abd El-Rehim DM, et al. Morphological and immunophenotypic analysis of breast carcinomas with basal and myoepithelial differentiation. J Pathol 2006;208:495-506.

17 Tsuda H, Takarabe T, Hasegawa F, et al. Large, central acellular zones indicating myoepithelial tumor differentiation in high-grade invasive ductal carcinomas as markers of predisposition to lung and brain metastases. Am J Surg Pathol 2000;24:197-202.

18 Fulford LG, Easton DF, Reis-Filho JS, et al. Specific morphological features predictive for the basal phenotype in grade 3 invasive ductal carcinoma of breast. Histopathology 2006;49:22-34.

19 Reis-Filho JS, Milanezi F, Steele D, et al. Metaplastic breast carcinomas are basal-like tumours. Histopathology 2006;49:10-21.

20 Jacquemier J, Padovani L, Rabayrol L, et al. Typical medullary breast carcinomas have a basal/myoepithelial phenotype. J Pathol 2005;207:260-268.

21 Laakso M, Loman N, Borg A, et al. Cytokeratin 5/14positive breast cancer: true basal phenotype confined to BRCA1 tumors. Mod Pathol 2005;18:1321-1328.

22 Foulkes WD, Brunet JS, Stefansson IM, et al. The prognostic implication of the basal-like (cyclin E high/ p27 low/p53+/glomeruloid-microvascular-proliferation+) phenotype of BRCA1-related breast cancer. Cancer Res 2004;64:830-835.

23 Turner N, Reis-Filho JS. Basal-like breast cancer and the BRCA1 phenotype. Oncogene 2006;25:58465853.

24 Palacios J, Honrado E, Osorio A, et al. Re: Germline BRCA1 mutations and a basal epithelial phenotype in breast cancer. J Natl Cancer Inst 2004;96:712-714; author reply 4.

25 Robson ME, Chappuis PO, Satagopan J, et al. A combined analysis of outcome following breast cancer: differences in survival based on BRCA1/BRCA2 muta- tion status and administration of adjuvant treatment. Breast Cancer Res 2004;6:R8-R17.

26 Chappuis PO, Goffin J, Wong N, et al. A significant response to neoadjuvant chemotherapy in BRCA1/2 related breast cancer. J Med Genet 2002;39:608-610.

27 Turner N, Tutt A, Ashworth A. Hallmarks of 'BRCAness' in sporadic cancers. Nat Rev Cancer 2004;4: 814-819.

28 Turner N, Reis-Filho JS, Russel AM, et al. BRCA1 down-regulation in sporadic basal-like breast cancer. Oncogene 2006;1-7.

29 Graham V, Khudyakov J, Ellis P, et al. Sox2 functions to maintain neural progenitor identity. Neuron 2003;39:749-765.

30 D'Amour KA, Gage FH. Genetic and functional differences between multipotent neuronal and pluripotent embryonic stem cells. Proc Natl Acad Sci USA 2003;30:11866-11872.

31 Chickarman V, Troein C, Nuber UA, et al. Transcriptional dynamics of the embryonic stem cell switch. PLoS Comput Biol 2006;2:1080-1092.

32 Hemmati HD, Nakano I, Lazareff JA, et al. Cancerous stem cells can arise from pediatric brain tumors. Proc Natl Acad Sci USA 2003;9:15178-15183.

33 Carlin R, Davis D, Weiss M, et al. Expression of early transcription factors Oct4, Sox2 and Nanog by porcine umbilical cord (PUC) matrix cells. Reprod Biol Endocrinol 2006;4:8.

34 Katoh Y, Katoh M. Comparative genomics on SOX2 orthologs. Oncol Rep 2005;14:797-800.

35 Kuroda T, Tada M, Kubota H, et al. Octamer and Sox elements are required for transcriptional cis regulation of Nanog gene expression. Mol Cell Biol 2005;25: 2475-2485.

36 Chew JL, Loh YH, Zhang W, et al. Reciprocal transcriptional regulation of Pou5f1 and Sox2 via the Oct4/Sox2 complex in embryonic stem cells. Mol Cell Biol 2005;25:6031-6046.

37 Mansukhani A, Ambrosetti D, Holmes G, et al. Sox2 induction by FGF and FGFR2 activating mutations inhibits Wnt signaling and osteoblast differentiation. J Cell Biol 2005;168:1065-1076.

38 Takemoto T, Uchikawa M, Kamachi Y, et al. Convergence of Wnt and FGF signals in the genesis of posterior neural plate through activation of the sox2 enhancer N-1. Development 2006;133:297-306.

39 Korkola JE, Houldsworth J, Chadalavada RSV, et al. Down-regulation of stem cell genes, including those in a $200-\mathrm{kb}$ gene cluster at $12 \mathrm{p} 13.3$, is associated with in vivo differentiation of human male germ cell tumors. Cancer Res 2006;66:820-827.

40 Rao M. Conserved and divergent paths that regulate self-renewal in mouse and human embryonic stem cells. Dev Biol 2004;275:269-286.

41 van Raag TJ, Moore KB, Iordanova I, et al. Frizzled 5 signaling governs the neural potential of progenitors in the developing Xenopus retina. Neuron 2005;46: 23-36.

42 Wessels LF, van Welsem T, Hart AA, et al. Molecular classification of breast carcinomas by comparative genomic hybridization: a specific somatic genetic profile for BRCA1 tumors. Cancer Res 2002;62:7110-7117.

43 van Beers $\mathrm{EH}$, van Welsem $\mathrm{T}$, Wessels $\mathrm{LF}$, et al. Comparative genomic hybridization profiles in human BRCA1 and human BRCA2 breast tumors highlight differential sets of genomic aberrations. Cancer Res 2005;65:822-827. 
44 Bergmaschi A, Kim YH, Wang P, et al. Distinct patterns of DNA copy number alteration are associated with different clinicopathological features and gene-expression subtypes of breast cancer. Genes Chromosomes Cancer 2006;45:1033-1040.

45 Palacios J, Honrado E, Osorio A, et al. Immunohistochemical characteristics defined by tissue microarray of hereditary breast cancer not attributable to BRCA1 or BRCA2 mutations: differences from breast carcinomas arising in BRCA1 and BRCA2 mutation carriers. Clin Cancer Res 2003;9:3606-3614.

46 Rodríguez-Pinilla SM, Sarrió D, Honrado E, et al. Vimentin and laminin expression is associated with basal-like phenotype in both sporadic and BRCA1associated breast carcinomas. J Clin Pathol 2006, (published on-line 14 November 2006).

47 Pinilla SM, Honrado E, Hardisson D, et al. Caveolin-1 expression is associated with a basal-like phenotype in sporadic and hereditary breast cancer. Breast Cancer Res Treat 2006;99:85-90.

48 Simpson PT, Gale T, Reis-Filho JS, et al. Distribution and significance of 14-3-3 sigma, a novel myoepithelial marker, in normal, benign, and malignant breast tissue. J Pathol 2004;202:274-285.

49 Lakhani SR, Van De Vijver MJ, Jacquemier J, et al. The pathology of familial breast cancer: predictive value of immunohistochemical markers estrogen receptor, progesterone receptor, HER-2, and p53 in patients with mutations in BRCA1 and BRCA2. J Clin Oncol 2002; 20:2310-2318.

50 Lakhani SR, Jacquemier J, Sloane JP, et al. Multifactorial analysis of differences between sporadic breast cancers and cancers involving BRCA1 and BRCA2 mutations. J Natl Cancer Inst 1998;90: 1138-1145.

51 Lakhani SR, Reis-Filho JS, Fulford L, et al. Prediction of BRCA1 status in patients with breast cancer using estrogen receptor and basal phenotype. Clin Cancer Res 2005;11:5175-5180.

52 Foulkes WD, Stefansson IM, Chappuis PO, et al. Germline BRCA1 mutations and a basal epithelial phenotype in breast cancer. J Natl Cancer Inst 2003;95: 1482-1485.

53 Arnes JB, Brunet JS, Stefansson I, et al. Placental cadherin and the basal epithelial phenotype of BRCA1related breast cancer. Clin Cancer Res 2005;11:40034011.

54 Carter MR, Hornick JL, Lester S, et al. Spindle cell (sarcomatoid) carcinoma of the breast: a clinicopathologic and immunohistochemical analysis of 29 cases. Am J Surg Pathol 2006;30:300-309.

55 Jones C, Ford E, Gillett C, et al. Molecular cytogenetic identification of subgroups of grade III invasive ductal breast carcinomas with different clinical outcomes. Clin Cancer Res 2004;10:5988-5997.

56 Palacios J, Honrado E, Osorio A, et al. Phenotypic characterisation of BRCA1 and BRCA2 tumors based in a tissue microarray study with 37 immunohistochemical markers. Breast Cancer Res Treat 2005;90: $5-14$.

57 Leibl S, Gogg-Kammerer M, Sommersacher A, et al. Metaplastic breast carcinomas: are they of myoepithelial differentiation? Immunohistochemical profile of the sarcomatoid subtype using novel myoepithelial markers. Am J Surg Pathol 2005;29:347-353.

58 Reis-Filho JS, Milanezi F, Paredes J, et al. Novel and classic myoepithelial/stem cell markers in metaplastic carcinomas of the breast. Appl Immunohistochem Mol Morphol 2003;11:1-8.

59 Janssen EA, Baak JP, Guervos MA, et al. In lymph node-negative invasive breast carcinomas, specific chromosomal aberrations are strongly associated with high mitotic activity and predict outcome more accurately than grade, tumour diameter, and oestrogen receptor. J Pathol 2003;201:555-561.

60 Boiani M, Scholer HR. Regulatory networks in embryoderived pluripotent stem cells. Nat Rev Mol Cell Biol 2005;6:872-884.

61 Tsukamoto T, Miroshita T, Tatematsu M. Gastric and intestinal mixed-type intestinal metaplasia: aberrant expression of transcription factors and stem cell intestinalization. Gastric Cancer 2006;9:156-166.

62 Sanada Y, Yoshida K, Konishi K, et al. Expression of gastric mucin MUC5AC and gastric transcription factor Sox2 in ampulla of vater adenocarcinoma: comparison between expression patterns and histologic subtypes. Oncol Rep 2006;15:1157-1161.

63 Tsukamoto T, Miroshita T, Mihara M, et al. Sox2 expression in human stomach adenocarcinomas with gastric and gastric-and-intestinal-mixed phenotypes. Histopathology 2005;46:649-658.

64 Sanada Y, Yoshida K, Ohara M, et al. Histopathologic evaluation of stepwise progression of pancreatic carcinoma with immunohistochemical analysis of gastric epithelial transcription factor Sox2; comparison of expression patterns between invasive components and cancerous or nonneoplastic intraductal components. Pancreas 2006;32:164-170.

65 Tatematsu M, Tsukamoto T, Inada K. Stem cells and gastric cancer: role of gastric and intestinal mixed intestinal metaplasia. Cancer Sci 2003;94:135-141.

$66 \mathrm{Li}$ XL, Eishi Y, Bai YQ, et al. Expression of the SRYrelated HMG box protein SOX2 in human gastric carcinoma. Int J Oncol 2004;24:257-263.

67 Prasad NB, Biankin AV, Fukushima N, et al. Gene expression profiles in pancreatic intraepithelial neoplasia reflect the effects of Hedgehog signaling on pancreatic ductal epithelial cells. Cancer Res 2005;65:1619-1626.

68 Sattler HP, Lensch R, Rohde V, et al. Novel amplification unit at chromosome 3q25-q27 in human prostate cancer. Prostate 2000;45:207-215.

69 Bertucci F, Finetti P, Cervera N, et al. Gene expression profiling shows medullary breast cancer is a subgroup of basal breast cancers. Cancer Res 2006;66:4636-4644.

70 Jones C, Nonni AV, Fulford L, et al. CGH analysis of ductal carcinoma of the breast with basaloid/myoepithelial cell differentiation. Br J Cancer 2001;85: $422-427$.

71 Letessier A, Sirconlomb F, Ginestier C, et al. Frequency, prognostic impact, and subtype association of 8p12, 8q24, 11q13, 12p13, 17q12, and 20q13 amplifications in breast cancers. BMC Cancer 2006;6:245 (in press).

72 Monaghan P, Clarke CL, Pernsinghe NP, et al. Epidermal growth factor receptor expression on human breast luminal and basal cells in vitro. Epithelial Cell Biol 1995;4:52-62.

73 van Agthoven T, Timmermaus M, Foekens JA, et al. Differential expression of estrogen, progesterone and epidermal growth factor receptors in normal, benign, and malignant human breast tissues using dual staining immunohistochemistry. Am J Pathol 1994; 144:1238-1246. 
74 Korsching E, Packeisen J, Liedtke C, et al. The origin of vimentin expression in invasive breast cancer: epithelial-mesenchymal transition, myoepithelial histogenesis from progenitor cells with bilinear differentiation potential? J Pathol 2005;206:451-457.

75 Reis-Filho JS. Re: Korsching et al. The origin of vimentin expression in invasive breast cancer: epithe- lial-mesenchymal transition, myoepithelial histogenesis or histogenesis from progenitor cells with bilinear differentiation potential? J Pathol 2005;206: 451-457.

76 Asselin-Labat M-L, Shackleton M, Stingl J, et al. Steroid hormone receptor status of mouse mammary stem cells. J Natl Cancer Inst 2006;98:1011-1014. 